u Zagrebu

stjepo.bartulica@unicath.hr

\title{
Uzroci sekularizacije prema Christopheru Dawsonu
}

Abstract: Bartulica Stephen Nikola, Uzroci sekularizacije prema Christopheru Dawsonu (The Causes of Secularization by Christopher Dawson). "Poznańskie Studia Slawistyczne" 10. Poznań 2016. Publishing House of the Poznan Society for the Advancement of the Arts and Sciences, pp. 389-401. ISSN 2084-3011.

The article examines the root causes of the secularization of European culture by focusing on the writings of the English historian Christopher Dawson. Dawson's central argument is that every human culture is based on religion and, thus, European culture on Christianity. He identifies the root causes of secularization to be found in the Renaissance and Protestant Reformation movements, both of which facilitated the emergence of the modern nation-state, but in different ways. The Renaissance marked the coming of a new culture - a new way of life - which had its roots deep in the past and had been developing for centuries in the Mediterranean world. The Protestant Reformation, on the other hand, brought an end to the religious unity which had existed for centuries in Western Europe, and subsequently divided Europe along religious lines. These two movements essentially laid down the foundations of an alternative culture, one often unbeknown to its architects: a culture which was still very much influenced by Christian origins, but would become over time first the rival and later the successor of Christianity.

KeYwords: secularization; Renaissance; Protestant Reformation; nation-state; Christianity; culture; religion

\section{Uvod}

Christopher Henry Dawson prozvan je ,najznačajnijim katoličkim povjesničarem 20. stoljeća engleskog govornog područja" (Callahan 1973: 167). Bio je oštar kritičar suvremene zapadne kulture, a njegovi zaključci temeljili su se na najimpresivnijoj sintezi tumačenja povijesti čovječanstva. Nije ga lako svrstati niti u jednu akademsku disciplinu jer je u svojim djelima kombinirao i integrirao brojne discipline. Tijekom Dawsonovog života Thomas Stearns Eliot nazvao ga je jednim od najutjecajnijih mislilaca u Engleskoj (Scott 1992: 210). Nažalost, u posljednjih nekoliko desetljeća, 
a osobito nakon njegove smrti 1970. godine, Dawson je u velikoj mjeri zanemarivan od strane akademske zajednice. Nedavno se, međutim, ponovno pobudio interes za njegova opsežna razmatranja o kulturi i suvremenosti, osobito u Sjedinjenim Američkim Državama.

Tijekom Drugog svjetskog rata Dawson je u svojim člancima kao urednik časopisa „The Dublin Review” i kao zamjenik predsjednika organizacije i pokreta Mač Duha (engl. The Sword of the Spirit), pozivao sve kršćane na obranu svoje duhovne baštine od prijetnje totalitarizma. Takav ekumenski napor nije bio široko prihvaćen od ostale katoličke hijerarhije u Velikoj Britaniji; čvrsto su se suprostavili bilo kakvom pokušaju suradnje između različitih crkava. Dawsonovu poslijeratnu karijeru obilježila su dva prestižna akademska priznanja. Prvo je poziv da drži Gifford predavanja (1947.-1948.) na Sveučilištu u Edinburghu, predavanja koja su se općenito smatrala najistaknutijima u Velikoj Britaniji ${ }^{1}$. Ona su kasnije objavljena pod nazivom Religija i kultura te Religija i nastanak zapadne kulture. Drugo priznanje, deset godina kasnije, bilo je njegovo imenovanje za predstojnika Katedre rimokatoličkih studija na Sveučilištu Harvard koje je osnovao Chauncey Stillman.

I prije objave članka Sukob civilizacija Samuela Huntingtona (1996: 41-47), Dawson je tvrdio da Europa mora obnoviti svoju vjersku tradiciju kako bi mogla voditi otvoren i iskren dijalog s drugim svjetskim kulturama. Tvrdio je kako se svako društvo temelji na krajnjoj mogućnosti priznavanja zajedničkih načela i ideala, a ako ne zahtijeva moralnu ili duhovnu lojalnost svojih članova, osuđeno je na propast. U tom kontekstu osobito ga je brinula tendencija stvaranja sekularizirane kulture u kojoj se religija tretira kao strogo privatna stvar bez ikakvog značaja u svakodnevnom životu. Kod mnogih promatrača pobudila se sumnja u dugoročnu perspektivu europske integracije utemeljene prvenstveno na ekonomskim i političkim interesima (cf. Siedentop 2000; Ratzinger 2007; Weiler 2003; Mattei 2006). U posljednje vrijeme neki su autori, kao npr. Marcello Pera i George Weigel, skrenuli pažnju na ograničenja sekularnog svjetonazora te obojica u svojim radovima citiraju Dawsona kao autoritet u području europske kulture.

${ }^{1}$ Prijašnja Gifford predavanja držale su istaknute osobe, kao npr. Alfred North Whitehead, Etienne Gilson, Hannah Arendt, Friedrich von Hügel, Henri Bergson i Albert Schweitzer. Predavanja je osnovao Adam Lord Gifford 1888. godine. 
Dawson je tvrdio da je čovjek u europskom povijesnom kontekstu kao član sveopće Crkve posjedovao pravu vrstu duhovnog državljanstva čak i prije nego što je stekao politička prava. Prema njegovom mišljenju to je temeljno državljanstvo, u usporedbi s kojim je članstvo (pojedinca) u državi sporednog značaja. Dakle, čovjekova je osobnost slobodna i posjeduje apsolutnu duhovnu vrijednost koja je neusporedivo veća od bilo čega u gospodarskom ili političkom poretku. U Gifford predavanjima, koja je držao tijekom 1947. i 1948., Dawson je razradio svoj pogled na odnos religije i kulture, osobito kršćanstva i zapadne kulture. Započinje s tumačenjem jedinstvenosti kršćanstva u toku svog povijesnog razvoja u usporedbi s drugim svjetskim religijama. Dawson to sažima na sljedeći način:

\footnotetext{
Velike svjetske religije su, na neki način, velike rijeke svete tradicije koje teku kroz stoljeća i promijenjive povijesne krajolike, koje navodnjavaju i oplođuju. No, u pravilu ih ne možemo pratiti do njihovog izvora koji je izgubljen u neistraženim putevima daleke prošlosti. Uistinu je rijetkost naći kulturu čiji se cijeli tijek vjerskog razvoja može pratiti od početka do kraja u punom svjetlu povijesti. No, povijest kršćanstva je iznimka. Poznajemo povijesni razvoj kroz koji se kršćanstvo prvi put pojavilo: posjedujemo pisma utemeljitelja Crkve prvim kršćanskim zajednicama u Europi i možemo detaljno pratiti postupne faze prodora nove religije na Zapad (Dawson 1948: 12).
}

Nakon dokazivanja jedinstvenosti kršćanstva među svjetskim religijama, Dawson objašnjava zašto razvitak zapadne kulture predstavlja jedinstveno dostignuće u svjetskoj povijesti. Prema Dawsonovom mišljenju, dva su načela koja razlikuju zapadnu kulturu od ostalih svjetskih civilizacija: njezin misionarski karakter - prijenos kulture iz jednog naroda u drugi kroz niz duhovnih pokreta - i izražen dualizam između kulturnog života i političke moći.

\section{Tradicija dvojnog autoriteta kršćanstva}

Dawson inzistira na središnjoj važnosti proučavanja ranog srednjeg vijeka (engl. Dark Ages) kako bi se postiglo odgovarajuće razumijevanje kasnijeg razvoja europske kulture. Njegova povijesna vizija bila je pod jakim utjecajem svetog Augustina, a posebno augustinske hermeneutike dvaju gradova. Dawson je vjerovao kako je genijalnost svetog Augustina izravna posljedica tadašnje političke i kulturne situacije u sjevernoj Africi. 
Dawson je primijetio kako u pristupu sv. Augustina u povijesti nalazimo dualizam koji nije metafizički, nego je u prirodi moralan. Povijest uključuje dva koegzistirajuća principa koji su izraženi u individualnoj volji i društvu: zakon božanske ljubavi koja obnavlja i mijenja ljudsku prirodu i dinamizam samoljublja koji teži podjeli i sukobu. Ova dva načela istovremeno djeluju i stvaraju napetost u čovjeku i društvu u cjelini. Dawson naziva tu napetost ,dublji zakon duhovne dvojnosti i polarizacije” (Dawson 2002: 325).

Kako bi prikazao važnost augustinskog okvira za povijesni razvoj Zapada, Dawson ga uspoređuje s iskustvom kršćanstva na Istoku, koje nije imalo tako jasan dojam o eshatološkom i socijalnom dualizmu. Dawson je primijetio da su Bizantinci skloni promatrati Carstvo kao utjelovljenje univerzalnog duhovnog društva i tako ,,previdjeti ili smanjiti ključnu dvojnost Crkve i države" (Dawson 2002: 338). S povijesnog i sociološkog aspekta, bizantska kultura predstavljala je jedinstveni primjer već postojeće kulture koja se iznutra preobrazila uz pomoć religije. Dawson je vjerovao kako ovaj primjer potvrđuje njegovu tezu o ulozi religije u procesu stvaranja kulture.

Za ovaj je tekst ključno da ćemo vidjeti kako Dawson koristi dualizam sv. Augustina kao temelj za njegova izlaganja na teme kao što su totalitarizam, demokracija i moderna država općenito. Transpolitički karakter kršćanstva ne znači da je država u potpunosti sekularna. Točnije tumačenje kršćanskog položaja je da njegova doktrina Dva Grada podrazumijeva razliku, ali ne i odvajanje duhovnog i svjetovnog. Drugim riječima, kršćanstvo uči da Bog ne zahtijeva određeni oblik vlasti niti određene političke vođe, nego je vlast osnovana od strane Boga. U kršćanstvu djeluje suptilni paradoks: Bog određuje državu, ali Bog određuje državu u nereligiozne svrhe, ograničene svrhe ograničenog vremenskog kraljevstva. Primjena je ovog načela ključna ako želimo izbjeći tendenciju tretiranja države kao kvazi-božanskog entiteta.

Dawson je odlučno inzistirao da nije moguće razumjeti povijest Europe bez temeljitog proučavanja uloge kršćanstva u oblikovanju kulturnog identiteta europskih naroda kroz stoljeća. Baš kao što nije moguće analizirati proces industrijalizacije u 19. stoljeću bez prepoznavanja važnosti ekonomije, isto tako, tvrdi Dawson, nije moguće ispitati pokrete koji su oblikovali društvo ako se ignorira utjecaj religije. Dakle, prije elaboriranja 
o Dawsonovom pogledu na renesansnu i protestantsku reformaciju, potrebno je ukratko objasniti njegovo tumačenje kako su srednjovjekovna kulturna dostignuća, koja su dosegnula svoj vrhunac u 13. stoljeću, počela propadati.

Dawson se usredotočio na lik Dantea (1265.-1321.), koga je smatrao mostom između srednjovjekovnih i renesansnih načina izražavanja zapadne kulturne tradicije. Premda je Dante bio istinski kršćanin i katolik, tvrdio je kako više ne traži svoj ideal jedinstva u crkvi, nego u čovječanstvu, a on smatra da je Rimsko Carstvo božanski predodređeni sluga i instrument čovječanstva. U tom smislu, Dawson spominje kako se Danteov pogled na kulturu, pa tako i na povijest, znatno razlikuje od pogleda sv. Thomasa, a još i više od sv. Augustina (Dawson 2002: 255-257) ${ }^{2}$. U svom proučavanju Danteovih razmišljanja, Etienne Gilson piše: „Ako je Danteov genus humanum zaista prvi poznati izraz moderne ideje čovječanstva, možemo reći da se koncept čovječanstva prvi put predstavio europskoj svijesti samo kao sekularizirana imitacija vjerskog poimanja Crkve" (Gilson 1949: 179).

Dawson je tvrdio da se Danteova kršćanska razmišljanja po prvi put dotiču zemaljskog i svjetovnog grada kao autonomnog, svrsishodnog poretka, a ne podređenog Crkvi. Prema Danteu, cilj civilizacije može se postići samo univerzalnim društvom koje zahtijeva političko ujedinjenje čovječanstva u jednu svjetsku državu. Dawson tvrdi kako unatoč tome što Danteov ideal univerzalne države proizlazi iz srednjovjekovnog poimanja kršćanstva te iz tradicije Svetog Rimskog Carstva, njegovi izvori nisu isključivo kršćanski. On je bio pod utjecajem političkih i etičkih ideala grčkog humanizma, kojeg je predstavljala Aristotelova etika i romantične idealizacije klasične povijesti, te njegove odanosti starom Rimu. Danteov pogled na Rimsko Carstvo razlikovao se od pogleda sv. Augustina i Dawson tvrdi kako on ,to ne smatra djelom ljudskog ponosa i ambicije, nego svetim gradom kojeg je Bog odredio kao instrument božanske svrhe ljudskog roda" (Dawson 2002: 256).

To uzvišenje države s povijesnog je gledišta značajno iz razloga što označava prijelaz od srednjovjekovnog uma do renesansnog duha u društveno-političkom smislu. Prema Dawsonu, idealizacija je klasične antike

\footnotetext{
${ }^{2}$ Kako bi identificirao izvor razlike između Dantea i sv. Thomasa, Dawson ističe proze Dantea - Il Convivio i De Monarchia - ali ne Danteove velike pjesme.
} 
u velikoj mjeri utjecala na stav ljudi renesanse prema suvremenoj državi i time pridonijela sekularizaciji europske kulture. On primjećuje kako se „talijanski grad-država i kraljevstva zapadne Europe više nisu smatrali organskim članovima kršćanske zajednice, nego autonomnim svjetovima koji nisu priznavali veću kaznu od volje za moći” (Dawson 2002: 257). Prema tome, povijest Europe od 15. stoljeća pa nadalje ,je sve više bila povijest razvoja ograničenog broja suverenih država kao nezavisnih centara moći te povijest neprestanog suparništva i sukoba između njih" (Dawson 2002: 257).

\section{Renesansa}

U dosadašnjem razmatranju Dawsonovih razmišljanja vidjeli smo da je princip jedinstva od velike važnosti. Dawson je smatrao da je civilizacija srednjovjekovnog kršćanstva ovisna o crkvenoj organizaciji Europe ili jednostavno da je Katolička crkva ujedinjavajući čimbenik mnogim polunezavisnim kneževinama i društvima koja su zajedno činila dio šireg društva - kršćanski narod. To jedinstvo, koje je postignuto kroz nekoliko stoljeća, počelo se rušiti nastankom renesanse u južnoj Europi i reformacije u sjevernoj Europi. Kao što je ranije spomenuto, ta dva pokreta su inspirirana vrlo različitim čimbenicima, ali su oba doprinijela odvajanju religije od kulture.

Dawson je smatrao i renesansu i reformaciju pobunama protiv srednjovjekovnog kršćanskog poretka, ali ta su dva pokreta bila toliko daleka u duhu te su ,često djelovala kao neprijatelji više nego saveznici” (Dawson 1972: 6). Duh renesanse bio je svjetski i antropocentričan u prirodi te se utjecaj pokreta proširio po cijeloj Europi prelazeći političke i nacionalne granice. Dawson je vjerovao kako su humanisti odbili ovisnost o nadnaravnom i na taj način odvojili vjeru od razuma te usmjerili svoje napore prema toj novoj neovisnoj racionalnoj sferi. Ljudi renesanse okrenuli su se od vječnosti i apsolutnosti prema svijetu prirode i ljudskog iskustva. Etos renesanse bio je sklon smatranju čovjeka kao mjere svih stvari i nastojao je emancipirati ljudski život od njegove ovisnosti o natprirodnim. Međutim, Dawson je tvrdio da prvobitna namjera ljudi renesanse nije bila motivirana protuvjerskim stavovima, ali njihove ideje jesu u konačnici dovele do sekularizacije kulture. 
Dawson je inzistirao kako je renesansa obilježila dolazak nove kulture - novog načina života - čiji korijeni sežu daleko u prošlost i koja je stoljećima nastajala u mediteranskom svijetu. Ta nova kultura mogla se razvijati samo u talijanskim gradovima, a prije svega u samoupravnim republikama poput Firence, gdje je nastajala nova obrazovna laička klasa s političkim pravima i građanskom svješću.

Ideal kontemplativnog života zamijenila je vita activa, koja je stekla sve šire prihvaćanje u ljudskoj svijesti. To je dovelo do nove vrste humanizma - humanizma ukorijenjenog u ,novoj filozofiji političkog angažmana i aktivnog života" (Baron 1966: 459) te posvećenog obilježavanju republikanskih sloboda. Ovo je dovelo do naziva ,građanski humanizam", koji označava određenu formulaciju republikanske svijesti i njezinih problema.

Premda je renesansa pridonijela sekularizaciji Europe, moglo bi se reći da nije sama po sebi bila nereligiozna. Prema Dawsonovom mišljenju, Desiderius Erasmus i sv. Thomas More bili su bliži tom pokretu nego Niccolo Machiavelli (Dawson 1949: 4-6). Dawson je primijetio kako je humanizam povratak prirodi i ponovno otkrivanje čovjeka i prirodnog svijeta. No, autor otkrića, aktivni sastavni dio promjene nije bio prirodan čovjek, bio je to čovjek kršćanin, ljudsko biće „kreirano tijekom deset stoljeća asketskom disciplinom i intenzivnim njegovanjem unutarnjeg života" (Dawson 1985: 89). Iz akumuliranih resursa njihove kršćanske prošlosti stekli su duhovnu energiju za osvajanje materijalnog svijeta i stvaranje nove sekularne kulture. Zapravo, nestanak je kršćanskog elementa u humanizmu kasnije doveo do čiste racionalizacije prosvjetiteljstva. Dawson je tvrdio da je kršćanstvo pravi izvor humanističkih vrijednosti te da ono posjeduje duhovnu dinamiku koja je potrebna za očuvanje tih vrijednosti kroz vrijeme.

\section{Protestantska reformacija}

U svojim spisima o povijesti Europe Dawson stalno naglašava kako je protestantska reformacija predstavljala dramatičan događaj za kršćanski poredak koji se izgrađivao stoljećima. U Dijeljenju kršćanstva (engl. The Dividing of Christendom) on tvrdi sljedeće: 
Nije pretjerano reći da su sudbina kršćanske kulture i razvoj moderne civilizacije utvrđene ili uvjetovane ratnim stanjem koje je postojalo između kršćana od reformacije do revolucije - prvo, stoljeće građanskog rata u užem smislu, a zatim stoljeće ili više stoljeća hladnog rata i antagonizma. Iako danas kršćani barem izlaze iz te atmosfere mržnje i nepovjerenja, moderni kršćanski svijet je još uvijek podijeljen vjerskim granicama utvrđenim još u doba tog vjerskog sukoba. Ova velika vjerska kataklizma je promijenila tijek povijesti i promijenila lice zapadne kulture za doba koja dolaze. Nemoguće je ignorirati tu mračnu i tragičnu stranu religijske povijesti; jer ako se s njom ne suočimo, ne možemo razumjeti neizbježni karakter kretanja sekularizacije (Dawson 1965: 10-11).

Dawson koristi izraze poput kataklizma, katastrofa i tragično kako bi opisao protestantsku reformaciju. Prema Dawsonovom mišljenju, reformacija se dogodila jer je postojanje jedinstvenog međunarodnog društva pod vodstvom Crkve bilo u suprotnosti s novim svjetovnim poretkom izraženim u državama i nacionalnim monarhijama. Glavni je argument ove teze što Dawson vjeruje kako je kolaps vjerskog jedinstva u Europi neizbježno doveo do sekularizacije kulture. Više od znanosti ili čak i humanizma, potreba za sekularnim političkim rješenjem za vjerske probleme na kraju je dovela do uklanjanja religije iz javnog života.

Dawson je vjerovao kako je teško dočarati veličinu štete nanesene kršćanskoj kulturi u stoljeću vjerskog sukoba koje je slijedilo razdoblje reformacije. Čak i unutar protestantskog svijeta vjerska je polemika postala uzrok društvenog sukoba ili opravdanje za isti, kao što je bio slučaj s građanskim ratom u Engleskoj. Taj rat, Dawson je tvrdio, jasno je pokazao značaj uzaludnosti i iracionalnost vjerskog sukoba u kojem je „svaka vojna pobjeda dovela do svježih podjela i daljnjih sukoba dok nikakvo rješenje nije moguće osim iscrpljujućeg i razočaranog povratka tradicionalnom poretku u crkvi i državi” (Dawson 1965: 10-11). On je zaključio da je ovaj neuvjerljivi religiozni sukob pripremio put za sekularizaciju europske kulture, iako to nije nužno bila namjera od strane samih aktera.

U pogledu rasta moći nacija-država, Dawson je na reformaciju gledao kao na nešto katastrofalno. Prema Dawsonovom mišljenju, ostali nacionalistički pokreti možda nikada ne bi uzeli maha da reformacija nije poticala još uvijek latentne barbarske nacionalizme u Europi. O Lutheru Dawson piše:

Njegova originalnost nije proizlazila iz njegovog intelektualnog položaja, nego iz snage njegovog emocionalnog života. On utjelovljuje pobunu probuđenog njemačkog nacionalnog duha protiv svakog utjecaja koji se činio stranim ili represivnim doživljajem; 
protiv asketizma i svega što je preispitivalo slobodno izražavanje prirodnih nagona, protiv intelektualizma Aristotela i sv. Thomasa, protiv cijele latinske tradicije, i prije svega protiv rimske kurije i njenjih talijanskih dužnosnika koji su za Dawsona bili predstavnici anti-Krista i veliki neprijatelji njemačke duše (Dawson 1965: 142).

Dawson je vjerovao da je, poput svih nacionalizama, Luther odbacio složenost kršćanstva - njegovu suptilnu, ali unitarnu visoku kulturu i policentrični politički poredak. U Napretku i religiji (engl. Progess and Religion) on citira Nietzschea, koji je opisao reformaciju kao „duhovnu seljačku bunu” (orig. Bauernaufstand), te je „u cijelom njezinom opsegu bila indignacija jednostavnosti protiv nečeg kompliciranog" (Dawson 1965: 71). Dawson je tvrdio kako je njemačka nacionalna ogorčenost protiv talijanskog papinstva i želje knezova da se njihovi ekonomski, politički i materijalni problemi rješavaju na račun Crkve bila motiv i snaga koja je prouzročila reformaciju, ne samo u Njemačkoj gdje su bili najjači, nego i u cijeloj sjevernoj Europi. Konačno, zaključuje kako je „,nemoguće dočarati u kojoj su mjeri religija i politika i kultura bile međusobno povezane u njemačkoj revoluciji” (Dawson 1965: 74). Po Dawsonovom mišljenju, reformatori nisu doveli do reformacije Crkve, već do reformacije srednjovjekovne države na račun Crkve.

Zbog Lutherovih primjedbi o statusu i ovlasti Crkve on je odbacio sva prava crkvenih vlasti na nadležnost nad svjetovnim poslovima. Osim toga, upravo je njegovo glavno vjerovanje u to kako Crkva nije ništa više nego congregatio fidelium uskratilo pravo na bilo kakvu odvojenu nadležnost. Isto tako smatra da ako Crkva nije ništa više od congregatio fidelium, onda svjetovne vlasti moraju imati isključivo pravo na izvršavanje svih prisilnih ovlasti, uključujući ovlast nad Crkvom. Luther naglašava ovaj argument na početku svog apela, gdje ustvrđuje kako „budući da Bog određuje svjetovnoj vlasti kažnjavanje zla i štićenje dobra, trebalo bi joj dati slobodu u obavljanju dužnosti u kompletnom kršćanstvu i to bez ograničenja i bez obzira na osobe te utjecaja na Papu, biskupe, svećenike, časne sestre ili bilo koga drugog" (Dawson 1965: 130). To je kritična točka u smislu političke filozofije jer zapravo označava kraj ogromne teorijske bitke koja se vodila tijekom cijelog srednjeg vijeka od strane protagonista regnuma i sacerdotiuma.

U pogledu Luthera Dawson je smatrao kako je, unatoč tomu što je bio „teološki revolucionaran”, bio i „socijalno konzervativan, odan svom caru i njegovom knezu i temperamentno nesklon bilo kakvoj socijalnoj 
revoluciji”" (Dawson 1965: 90). Lutherova najvažnija rasprava o političkim i društvenim pitanjima - Svjetovna vlast: do koje mjere biti joj pokoran (Von weltlicher Obrigkeit, wie weit man ihr Gehorsam schuldig sei) - izričito priznaje kako sve političke vlasti potječu od Boga (Skinner 1978: 15). On tretira Novi zavjet, naročito dekrete sv. Pavla, kao konačni autoritet za sva temeljna pitanja o pravilnom vođenju društvenog i političkog života. Nadalje, Luther tvrdi kako je politički položaj koji propisuje Novi zavjet u potpunosti pokoran svjetovnim vlastima.

Na kraju svoje rasprave o Svjetovnoj vlasti Luther postavlja pitanje: Što ako je knez u krivu? Jesu li ga njegovi ljudi i tada dužni slijediti? Lutherov je odgovor na to pitanje: „Ne, jer nije ničija dužnost činiti zlo” (Luther 1962: 125). On tretira sve tvrdnje o apsolutnoj moći kao nerazumijevanje i izopačenost autoriteta koji je Bog dao vladarima. Unatoč njegovom naglašavanju ideje da se nikada ne smije poštivati bezbožničkog vladara, Luther naglašava kako se takvom vladaru nikada ne smije aktivno usprotiviti. Budući da su sve ovlasti određene, to bi bilo isto kao otpornost Božjoj volji, čak i u slučaju tiranina. On izričito navodi kako se tiraniji „ne treba oduprijeti, nego je treba pretrpjeti” (Luther 1962: 112). Tijekom turbulentnih 1520-ih godina Luther je stavio najveći naglasak na doktrinu nesuprostavljanja. Dijelio je zajednički strah reformatora o tome kako se njihovi zahtjevi za vjerskim promjenama mogu dovesti u vezu s političkim radikalizmom. Dawson je napisao kako je došlo do toga da se vjerska revolucija koju je započeo Luther u stvari poistovjećuje s Revolucijom kneževa, koju su činile „najveće društveno-političke snage proizašle iz raspada ili preoblikovanja tradicionalnog jedinstva Carstva" (Dawson 1965: 93).

Po Dawsonovom mišljenju, napredak je reformacije, naravno, pogodovao moći knezova, prvenstveno nakon što je ukidanje crkvenog posjeda i oduzimanje crkvenog bogatstva pomoglo knezovima u proširenju i konsolidaciji njihovih država. Osim toga, uspostava luteranske teritorijalne crkve, pod nadzorom i kontrolom kneza, predstavljala je potpunu reorganizaciju društva u korist kneza koji je stekao gotovo apsolutni vjerski autoritet $^{3}$. Dawson je identificirao Filipa od Hessena kao najvažnijeg pro-

${ }^{3}$ Ova je činjenica vrlo ironična jer je Lutherova originalna namjera bila osloboditi ljudsku savjest od autoriteta. Luther se protivio svakom kretanju prema slobodi u društveno-političkoj sferi, kao u slučaju seljačke bune i anabaptističkog pokreta. 
testantskog kneza zbog njegove uloge u stvaranju Lige Schmalkalden ${ }^{4}$, po kojoj su protestanti postali politički faktor u Europi.

Iako je Luther bio kreativna snaga iza revolucionarnog pokreta koji je uništilo jedinstvo kršćanstva, Dawson je tvrdio kako su ,njegova dostignuća kao osnivača i organizatora bila relativno mala i prilično je upitno bi li luteranizam, u slučaju da je bio prepušten vlastitim resursima, izdržao katoličku reakciju koja je uslijedila" (Dawson 2013: 27). Luteranizam je imao dvosmislen dugoročni utjecaj na kulturu Europe. S jedne je strane bio pobuna protiv vjerske vlasti koja je dovela do emancipacije pojedinaca iz struktura Katoličke crkve. S druge je strane bio politički iznimno konzervativan i nije doveo do veće slobode u svjetovnoj sferi.

\section{Zaključak}

Dawsonova sposobnost za percipiranje kulturne stvarnosti kao cjeline, umjesto samo jednog dijela, omogućila mu je identifikaciju korijena uzroka društvenih promjena, kao i utjecaj na kulturu. Na primjer, renesansa je razdoblje kada je Europa prolazila kroz velike promjene i kada je nastajao novi svijet. U 15. stoljeću odjednom vidimo kako se zapadnom čovjeku otvorio novi svijet zahvaljujući otkrićima do kojih je došlo uz pomoć novih tehnika koje su se postupno razvile u srednjem vijeku. Dawson pridaje iznimnu važnost velikim napretcima u znanosti i znanju. Čovjekov pogled na stvarnost znatno se promijenio, zajedno s njegovom koncepcijom prirode kao žive cjeline koja ima svoje vječne zakone.

U svojim djelima koja se bave tom temom Dawson je dosljedno shvaćao reformaciju kao društveno-politički, a ne kao teološki fenomen. Za njega je najvažnija činjenica da je protestantska reformacija u konačnici dovela do stvaranje moderne nacije-države te je izmijenila javnu ulogu religije u društvu. Iako možda ironično, to nije bila namjera Martina Luthera kada je započeo pobunu protiv Rima 1517., ali njegovi su postupci

\footnotetext{
${ }^{4}$ Liga Schmalkalden bila je obrambeni savez koji su oformile protestantske države Svetog Rimskog Carstva kako bi branile novoosnovane Luteranske crkve od napada cara Karla V. Osnovana je 1531. u Schmalkaldenu, u istočnoj Njemačkoj, a ligu su vodili Filip od Hessena i Ivan Frederick I. od Saske. Karlo je bio prisiljen dati joj de facto priznanje sve do 1544. kada se pomirio s Franjom I. od Francuske. Liga je efektivno uništila vojne sile 1547.
} 
u konačnici doveli do građanskog rata i trajnih podjela u Europi. Dawson je vidio Luthera kao njemačkog nacionalista koji je, nakon prethodnih nacionalista poput Wyclifa i Husa, utjelovio pobunu „,buđenja njemačkog nacionalnog duha". Dawson je tvrdio da je Luther pripremio put za sekularizaciju europske kulture i ukidanje objektivnih standarda napadajući prirodni zakon i stvarajući dualizam Zakona i Evanđelja.

Po njegovom mišljenju, renesansa i protestantska reformacija predstavljale su dva pokreta koji su radikalno promijenili kulturni okvir koji se razvijao stoljećima. Ta su dva pokreta u biti postavila temelje za alternativnu kulturu koja je često bila nepoznata vlastitim arhitektima: kultura koja je još uvijek bila pod jakim utjecajem kršćanskih korijena, ali je s vremenom najprije postala suparnik, a kasnije nasljednik kršćanstva. Jedna od ključnih promjena koja se dogodila u tom razdoblju ta je da je religija postala podređena državi po principu cuius regio eius religio, a to načelo se i dalje poštivalo u Europi, čak i kada države službeno više nisu bile kršćanske.

\section{Literatura}

Baron H., 1966, The Crisis of the Early Renaissance, Princeton.

Burckhardt J.,1990, The Civilization of the Renaissance in Italy, London.

Callahan D., 1973, Christopher Dawson, „Harvard Theological Review” br. 66/2, str. $161-176$.

Dawson C., 1948, Religion and the Rise of Western Culture, London.

Dawson C., 1949, Religion and Culture, London.

Dawson C., 1965, The Dividing of Christendom, New York.

Dawson C., 1972, The Gods of Revolution, New York.

Dawson C., 1985, Christianity and the New Age, Manchester.

Dawson C., 2001, Progress and Religion, Washington DC.

Dawson C., 2002, Dynamics of World History, Wilmington.

Dawson, C., 2013, The Movement of World Revolution, Washington DC.

Gilson E., 1949, Dante the Philosopher, New York.

Huntington S., 1996, The Clash of Civilizations and the Remaking of World Order, New York.

Luther M., 1962, Temporal Authority: to what Extent it Should be Obeyed?, Philadelphia.

Mattei R., 2006, De Europa: Tradici cristiane e sogni postmoderni, Florence.

Ratzinger J., 2007, Europe: Today and Tomorrow, San Francisco. 
Scott C., 1992, A Historian and His World: The Life of Christopher Dawson, New Brunswick.

Siedentop L., 2000, Democracy in Europe, London.

Skinner Q., 1978, The Foundations of Modern Political Thought, Cambridge.

Weiler J.J., 2003, Integration in an Expanding European Union: Reassessing the Fundamentals, London. 